\title{
The Flipped Classroom in Multimodal CBI College English Teaching
}

\author{
Yunru Chen \\ School of Foreign Languages \\ Wuhan Textile University \\ Wuhan, China \\ e-mail: yunru-chen@qq.com
}

\author{
Wei $\mathrm{He}$ \\ School of Foreign Languages \\ Wuhan Textile University \\ Wuhan, China \\ e-mail: 1649586842@qq.com
}

\begin{abstract}
Nowadays the vast amount of learning resources on the Internet and many new learning models like MOOCs have brought unprecedented impact on traditional College English teaching. In the light of the theory of multimodal discourse analysis, Content-Based Instruction and the idea of a flipped classroom, this paper intends to formulate an efficient and individualized mode for College English teaching by dint of advanced information technology and internet resources. In the proposed mode, the leading role of classroom teaching would be reversed to students, the function of multiple modalities in influencing teaching effect fully considered, and the acquisition of English embedded in learning subject matter in English. The present study may make a breakthrough in China' College English teaching reform by proposing a dynamic and interactive English teaching mode which is committed to stimulating students' passion for English learning and motivating them to conduct enquiry learning.
\end{abstract}

Keywords-CBI; College English; the flipped classroom; multimodality

\section{INTRODUCTION}

In 2007, China's ministry of education issued clear guidelines on the College English instruction that in light of the status quo of China's social development and the demand of international communication, College English teaching should be the aimed ultimately at developing the students' competence of the English language and also the mastery of English cultural literacy. It is also required that the principle of classified guidance and individualized education should be implemented and modern information technology should be made good use of to create new class culture which give students the leading role in classroom teaching. Nowadays the vast amount of learning resources on the Internet and new learning models like MOOCs ((Massive Open Online Courses) have sparked off a worldwide revolution in higher education, which have been brought unprecedented impact on college English classroom teaching in China. Theoretically based on the theory of multimodal discourse analysis (MDA), Content-Based Instruction (CBI), and the idea of flipped classroom, this paper intends to propose a new mode of College English teaching named the flipped classroom in multimodal CBI College English teaching. The present study might be pioneering work in applying those ideas cooperatively to College English teaching, and would pave the way for relevant practice in College English reform.

At the beginning, the theory of MDA, CBI and the idea of the flipped classroom are briefly reviewed in turn. Then formation of the flipped classroom in multimodal CBI College English teaching is discussed in detail. Furthermore, potential problems of the proposed mode in practice are analyzed in depth and corresponding solutions are also put forward. Finally, major findings and limitations are concluded and at the same time, suggestions for further study are made.

\section{LITERATURE REVIEW}

\section{A. Overview of Systemic-Functional MDA}

With the remarkable development of multimedia and computer technology, other semiotic resources such as visual image, sound and action is challenging the dominant role of language in mass media and communication, hence information transmission presents multimodality.

Systemic-Functional Linguistics is an approach to linguistics that considers language as a social semiotic system. It was developed by Michael Halliday. For Halliday, language is a system network and the grammatical or other features of language are described as sets of choices. He also holds that all languages involve three meta-functions which come into being simultaneously: ideational function, interpersonal function and textual function. Although originally conceived for the study of language, SystemicFunctional Grammar is widely used to analyze other semiotic resources. We will review the previous studies in this field as follows:

Since the mid 1980s, Hallidayan discourse analysis has begun to take meaning-making into serious consideration other than language. More and more semiologists are making attempts to associate De Saussure with the analysis of film and photography (Metz 1974, 1977; Barthes 1977). Jim Martin makes a breakthrough by putting forward "discourse semantics" (Martin 1992), and discourse analysis begins to 
move far beyond the original conception of text. Based upon Systemic-Functional framework, meaningful findings are made in the research with the focus on the studies of visual art, sculpture and spatial construction. Taking image as a social semiotic mode, Kress and van Leeuwen focus on the structure or "grammar" of visual design including color, perspective, framing and composition. Their work Reading Images (Kress \& van Leeuwen 1990) becomes the authority in interpreting visual communication. They propose that the semiotic tools in visual communication are delicately represented to realize some particular functions, namely, representational meaning, interactive meaning and compositional meaning which respectively correspond to ideational function, interpersonal function and textual function in Systemic-Functional Grammar. Van Leeuwen takes the lead by applying the Systemic-Functional Grammar into sound and music (van Leeuwen 1999). Meanwhile, some scholars begin to study the interrelationship among different meaning-making systems with the purpose to establish shared semiotic principles. Michael O'Toole (1994) makes the running in the study of the grammar within single semiotic resource and the grammatical relations between semiotic resources. His work The Language of Displayed Art gives definition to the functions of visual images as representational, modality and compositional. Lim (2004) puts forward an integrated multi-semiotic model as a "metamodel" for analyzing the use of language and image as semiotic resources. However, much work remains to be done to further improve the model to explain some dynamic semiotic resources like video.

In contrast, the study of MDA in china is still in its initial stage. Li Zhanzi (2003) firstly brings in the grammar of visual design proposed by Kress and van Leeuwen. Zhu Yongsheng (2007) articulates the definition of multimodality, the theoretical basis, methodology, and significance of MDA. $\mathrm{Hu}$ Zhuanglin points out the significance of enhancing people's general comprehension and identification on multimodal discourse. Zhang Delu (2009) deploys SystemicFunctional Linguistics to propose a synthetic theoretical framework for MDA. Based on their introductive work, the theory of MDA is beginning to be applied to different genres by Chinese scholars.

\section{B. Overview of Content-Based Instruction}

Defined as "the teaching of content or information in the language being learned with little or no direct or explicit effort to teach the language itself separately from the content being taught" (Krahnke, 1987), CBI is based on the notion that people learn a language more successfully when they use it as a means of acquiring information rather than as a goal itself. This notion can be justified by three important features of language: First of all, language is discourse-based, so language teaching should focus on meaningful content in discourse instead of single words, phrases or sentences. Secondly, the use of language involves integrated skills which are not independent from each other but correlated and usually synergistic in meaning making. Thirdly, language is purposeful, which means the use of language is a kind of communicative action with certain purpose. In this sense, the variety of the meanings of language is caused by the diversity of the purposes for which people use it, and the purposes can be recreational, vocational, social, or academic.

CBI is originated in St. Lambert's successful Immersion Program, in Montreal, Canada in the 1960s. Immersion Education is a pattern of foreign language instruction in which the target language is taken as the medium in which the regular school curriculum is taught. Since 1980s, Content-based approaches have been widely used in various settings of language teaching. Krashen's Input Hypothesis, the cognitive theory, the cooperative language learning provide the theoretical basis for CBI curriculum. In ContentBased Second Language Instruction (Brinton, 1989) and Content-Based Instruction in Foreign Language Education: Models and Methods (Stryker \& Leaver, 1997), the theory and practice of CBI in the larger context of second and foreign language education over the last few decades are discussed. Brinton (1989) believes that the principle of CBI can be applied to the design of courses for learners at any level of language learning and he proposes five teaching modes of CBI, namely Theme-based language instruction, Sheltered-content instruction, Adjunct language instruction, Team-teaching approach, Skill-based approach. Since CBI is an approach more than a method, no specific techniques or activities are stipulated in it. Consequently, teachers are free to choose any mode in classroom teaching as the situation dictates and there is also a large room for them to select the appropriate and effective techniques for each class. Stryker and Leaver (1997) claim that CBI can be at once a philosophical orientation, a methodological system, a syllabus design for a single course, or a framework for an entire program of instruction. To improve the effectiveness of CBI practice, Stoller (1997) proposes "Six-T" method which specifically refers to Theme, Text, Topic, Tread, Task and Transition.

In china, the study related to $\mathrm{CBI}$ has just begun in recent years. Wang Shixian (1994) does pioneering work in introducing the concept and basic modes of CBI. Since then, Sun Chunlei (2000) and many other scholars have worked on the theoretical and practice research of CBI. However, up to now, little has been done in carrying out systematic study of CBI practice in College English teaching in China.

\section{Overview of the flipped classroom}

In 2007, chemistry teachers in Woodland Park High School, Jonathan Bergmann and Aaron Sams thought up an idea to make-up missed lessons for absent students. They began to record lessons, and posted them online. Surprisingly, these courses online became popular with students very soon. Not just for making up missed lessons, students learned these online materials to review and reinforce classroom lessons. This idea of flipping the common instructional approach is named "the flipped classroom" or "the inverted classroom". In the flipped classroom, the traditional classroom is inverted through 
"moving the lectures outside the classroom and using learning activities to move practice with concepts inside the classroom" (Strayer 2012). The flipped classroom allows instructors to teach both content and process by using a student-centered learning environment (Kim et al. 2014). This approach encourages students' active engagement in higher-order tasks and their autonomy in their own learning (Hannafin et al. 1997). This type of teaching is commonly thought of as reversed teaching model, which is also referred to an inverted classroom technique (Lage et al. 2000; Mason et al. 2013), or alternatively classroom flip (Baker 2000) where technology or resources are used to arouse students' interest in language learning and thus get better results in teaching. In that case, an instructor can spend more time in interacting with students to apply the concepts and knowledge, instead of lecturing (Butt 2014). Bates and Galloway (2012) note that "It is an exhilarating feeling to be freed from the tyranny of content coverage to be able to have the time and space to focus on what really matters...Furthermore, this understanding did not come with a price of 'covering' less material: we are convinced that, largely through the students' efforts outside class, we covered as much content but uncovered a great deal more understanding".

Pierce and Fox (2012) consider the flipped classroom as a reversal of roles where what used to be class work (namely, the instructor-led lecture and student note taking) is done prior to class, while what used to be homework ( typically, assigned problems)is done in the scheduled class, thus it turns the traditional information transfer approach of teaching upside down (Mazur 2009). Bishop and Verleger (2013) provide a survey of current and prior research into the flipped classroom approach which shows that student show positive attitude towards this approach constantly. Ferreri and O'Connor (2013) redesign a large lecture course into a small-group learning course. Results indicate that students prefer the smaller class formats and achieved significantly better academic grades. In a large-enrolment physics course, Bates and Galloway (2012) require students to have introductory class through self-learning prior to attending the regular class and then have a guided discussion session during class time. Results indicate this teaching approach enhances students' engagement in class teaching and thus promotes students' learning effects. One issue highlighted by this teaching approach is the mental shift that requires academic staff to accept and embrace "an unstructured, contingent lecture experience in which the lecturer is no longer in complete control of" (Bates and Galloway 2012). Bates and Galloway described the payoff for this approach as "the potential for an inclusive and participatory classroom atmosphere".

By comparing the learning environments of an inverted introductory statistics class with a traditional one, Strayer(2012) finds that students in the inverted classroom approach are less satisfied with how the classroom structure oriented them to the learning tasks in the course while more open to cooperative learning in and innovative teaching methods. Alexander (2013) suggests the idea of partially flipping and making some of the resources available online. The partially flipped classroom concept is then undertaken by Dawes and Fox (2013) in a grade 11 math course. Mazur (2009) highlights the achievement gained through utilizing this approach, including detailed awareness of students' understanding and a higher-order learning occurring during class time. For the sake of effective application of CBI approach in practice, Stoller (1997) proposed "Six-T" method, to guide the curriculum design of CBI teaching. Here "Six-T" refers to Theme, Text, Topic, Thread, Task, and Transition.

However, the literature is scarce about the application of the flipped classroom to the College English teaching in China.

\section{RESULTS}

Firstly, the formation of the flipped classroom in multimodal CBI College English teaching is explained in detail. Secondly, through discussion, the necessity and feasibility of applying the proposed mode to College English teaching is testified; thirdly, corresponding coping strategies for potential problems in practice are put forward. At last, in view of major findings and limitations of this research, empirical study remains to be done.

\section{DISCUSSION}

In recent years, tentative efforts have been made by Chinese educators to improve College English teaching. The problems such as curriculum, methodology and teaching environment have always been the focus of attention in College English reform. The flipped classroom in multimodal CBI College English teaching is a daring attempt for the synergistic use of CBI, the flipped classroom teaching approach and the theory of MDA which are aimed at solving the problems in practice respectively as to how to select and arrange the teaching materials, who dominates the teaching, and how to choose and coordinate the modalities in teaching.

\section{A. Formation of the flipped classroom in multimodal CBI College English teaching \\ 1) Theme-based CBI mode}

$\mathrm{CBI}$ is effective in helping students achieve language proficiency through the study of subject matter. In this research, the application of CBI to College English teaching is aimed at solving the fundamental problems as to teaching content. Over the past few decades, College English teaching has always followed a grammatical-structural or skilledbased orientation, in which the curriculum focuses on form instead of meaning. CBI College English teaching takes the students' interests, needs, styles and motivations into consideration, and abandons the misconception that teaching language is to teach a set of rules of language without respect to the role of meaningful content. 
With a view to integrating English teaching with certain academic subject, the curriculum of CBI College English teaching has to include diverse themes and topics attached which are closely related their academic learning and their daily life. Thus, among these modes of CBI, Theme-based mode is most suitable for the College English curriculum. Since students are supposed to improve their English skills, to learn strategies to be applied in all subject areas, and to understand the culture of English-speaking people (Richards \& Rodgers, 2001), teachers should consider the linguistic, strategic and cultural objectives in designing Theme-based CBI curriculum and implement the following principles: Firstly, interesting, useful, and purposeful information content can be adopted in teaching with a view to increase students' motivation in English learning and promote learning effectiveness. Secondly, there exist certain areas of content which are thought to be more effective as teaching material for CBI than others. For example, Geography is "highly visual, spatial, and contextual; it leads itself to the use of maps, charts, and realia and the language and tends to be descriptive in nature with the use of 'to be', cognates, and proper names" (Stryker \&Leaver 1993). So it is advisable for teachers to conclude Geographic content in CBI College English teaching. Thirdly, students tend to learn best when they learn what they need. In other word, the teaching content should be selected according to students' specific needs. For instance, texts describing the real life are suitable for all college students regardless of their majors. However, the dissertations on various subjects should be only provided for the students in related majors. In the case of an academically focused program, "the language curriculum is based directly on the academic needs of the students and generally follows the sequence determined by a particular subject matter in dealing with the language problems which students encounter" ( Brinton et al. 1989). Fourthly, teachers should take students' English grounding and educational background into consideration so that the lesson could start with what the students have already known about the theme being discussed.

When it comes to the organization of teaching content, "Six-T" method is considered most effective in the practice of Theme-based CBI College English Teaching.

a) Theme: the decisive and foundamental ingredient in Theme-based instruction which determines whether CBI College Englsih course will be well-received by students and whether students will be motivated and inspired in Englsih learning. In deciding the theme, students' needs, interests, language competence, their majors together with the teachers' ability of handling the theme in question should be given full consideration. What's more, there should not be necessarily only one theme, but multiple themes covering society, culture, arts, politics, religion, and science can be included. It is worthy to be mentioned that, themes pertinent to students' majors are indispensable to their respective CBI College English learning. The habit of doing subject research through the medium of English may help students get the latest academic information and facilitate the international publishing of their research findings.

b) Text: primary teaching materials which do not only refer to text books, but also involve recordings, vedios, and other materials for listening and speaking training. In a fixed theme, teachers should select the texts which are interesting, authentic, informative, up to date, and within the limit of students. Attenion should also be paid to the diversity and logic order of the chosen texts so that the theme could be reinforced by those texts and students could acquire a more comprehenive knowledge of this theme.

c) Topics: the subject matters that revlove around the texts attached to each theme and steer the teaching activites in general. The selected topics should not be only interesting, meaningful and thought-provoking, but also distinctive and correlated. What's more, topics should be easy to handle, otherwise they would probably fail to interest and motivate students. With approachable topics, students will get well acquainted with the targeted theme, get essential knowlwge in that filed and become adept at using English to express their notions about these topics.

d) Threads: the clues, with which the correlation of themes, texts and even topics can be established. A clear-cut thread could create the integrity of the whole course which is useful in help students complete consolidation of knowledge by association.

e) Tasks: the assignmemts which can be devided into preview, classroom works, and homework. College English teaching has no reason to ignore language training covering vocabulary, grammar, expresion, stucture and other linguistic skills, however CBI doesn't allow pure language exercises. Students' communicative competence, learning capacity, and subject ability are also expected to be improved through their completing the tasks of certain subject matter. In fact, as the meaning of content become more complex and specialized, the language used to construe the meaning will accordingly become more complicated and distanced from ordinary use. Therefore, in setting tasks, familarity of subject matter, syntactic structure, and lexical meaning of the content are key parameters.

f) Transition: a reasonal passage that connects a theme/ text/ topic to one that follows. It plays an important role in forming a ligical thread.

2) Mutimodal teaching and learning

College English teaching is regarded as a communicative, dynamic, multimodal and social activity which involves a variety of modalities such as text, sound, image, and even gesture. In light of the theory of MDA, the role of those modalities in influencing teaching effect is reexamined.

On the promise of best teaching effect, teachers cautiously select and coordinate diverse modes and modalities to create a multimodal teaching environment. 
First of all, computer-assisted instruction is effective in facilitating multimodal teaching and learning. Secondly, through careful observation and intensive investigation, teachers could discover students' preference for modalities in different teaching activities. For instance, in word studying, teachers may probably find that students usually prefer to see pictures in comparing moss green, emerald green and olive green, but videos in identifying lock stitch, fastening stitch as well as pad stitch while samples in distinguishing cut velvet, over coating and lycra woolen goods. Thirdly, changes are needed in the layout of classroom. For example, tables and desks fastened to the floor can be replaced by folding training chairs which are more convenient for students to gather round in a circle when they are having group discussion. Fourthly, costumes and props are helpful in assisting situational teaching and communicative teaching such as simulating business negotiations and press launches. Fifthly, multimodal evaluation is must-needed because the traditional way of assessment neglects the active role of other non-verbal modalities in meaning-making.

\section{3) The flipped classroom}

To set up a flipped classroom in multimodal CBI

College English teaching, the basic principles are as follows:

a) Reversed Roles of teachers and students: Different from teacher-led College English courses, students are endowed with dominant role in the flipped classroom where teachers are more mentors, facilitators than lecturers. On the one hand, students can have their own shedules for out-ofclass learning, move at their own pace and study whatever they wish to. They are also free to choose whatever forms they like to present their research results. The personalized learning and self-determination stimulate students' passion for learning and cultivate their self-learning ability. On the other hand, teachers have to restrict their class instruction and try to help students by giving them advice on learning strategies and methods rather than knowledge itself.

b) Rearrangement of classroom teaching: In the flipped classroom, what is done in traditional College English class teaching and what is normally done as homework are inverted. Normally students firstly attend a lecture, listen to the teacher's explanantion and take notes. Then they are required to finish assignments in order to complete the internalzation of knowledge involved in the lecture. However, students in the flipped classroom should firslty finish reading materials and video lessons to obetain general knowledge about certain topic. When they come to class, dynamic class communication help them consolidate the knowledge they've got before class and finish the knowledge digestion and assimilation. Classroom is not only a place for teachers to give instructions but also a place for a free interchange of ideas. Presentation session is of vital importance in classroom teaching, through which teachers could see students' achievement, engagement, and difficulties and also get a better insight into students' interests and learning styles. Since teachers' lecturing time in class is limited, classroom time should be used more effectively and creatively. Class activities should include higher-level cognitive activities to inspire students' deeper thinking and more active engagement. In addition, useful and practical assignments could not only stimulate students to do further study but also pepare them for learning in the forthcoming period. These assignments could be finished through the group work, pair work, or individual work. With respect to the means of monitoring, modern communication tools such as QQ, Wechat and Weibo, together with information teaching management such as online learning database and open sourse learning platforms like Moodle are effective in assisting teachers keeping in close touch with students so as to follow students' psychological changes in learning and also monitor their self-learning and cooperative learning.

c) Video lessons: The flipped classroom requires students to learn concepts, principles, facts, and terms by themselves in out-of-class learning. Main sourse of learning materials is video lessons which are customized according to different teaching purposes together with students' English competence and learning preferences. This would be a demanding job for Englsih teachers to produce a fiveminute video lesson to explain clearly a concept or a principle in a bite-sized chunk. In producing such video lessons, teachers should pay attention to such factors as the length of video, the pace of instruction, the example used, and the visual effect. More attention should also be paid to the reasoning behind the examples so that the video lessons could effectively promote the coming activities in class time. What's more, as students become more open to interactive learning and enquiry learning, they tend to be increasingly unsatisfied with the learning tasks within the limit of the settled syllabus. Accordingly, the available learning resources online covering a wide range of subjects are popular with students, especially those released by some top universities and authorities. Moocs have become an important component of the out-of-class learning system.

\section{B. Potential problems in practice and corresponding solutions}

\section{1) Self-role cognition in teaching and learning}

Teachers' and students' awareness of their changed roles in teaching and learning is an essential prerequisite for the success of the proposed mode. For one thing, those students who have no idea of their obligations in learning may be initially resistant to the requirement that they should learn by themselves what used to be explained in class. Consequently, they may come unprepared to class and reluctant to participate in interactive learning during classroom teaching. To solve this problem, teachers are expected to give students detailed introduction to the proposed mode and define what exactly students are supposed to do and how to do it. They can also test students before class by giving a short quiz online to see whether students have mastered the elementary knowledge required for coming class. Meanwhile, the result of the quiz is also a hint for students to know whether they have met the 
requirement of teachers. For another, the greatest problem for teachers is how to limit lecturing in class and give students enough leeway for their personal learning. Teachers' priority is to define the main objectives of the course and offer guidance to students on how to attain these objectives. In other words, teachers' duty is not to impart knowledge but to pass on the means to gain knowledge.

\section{2) Strategies of evaluation}

Traditionally, students' performance is evaluated through tests and examinations which primarily focus on vocabulary, linguistic structure, grammar and other language skills. However, in the proposed mode, students are exposed to both the English language and subject matter in different domains and meanwhile their dynamic role has become a determining factor in teaching, so the traditional ways of assessment is obsolete. In that case, a new evaluation system is needed. Some specific strategies for evaluation are brought forward as follows:

a) Multimodal assessment: Generally speaking, in traditional college English teaching, written examinition is adopted as the major means to test stduents, in which text and sound are used as main modalities for reading, writing and listening test. However, since the proposed mode highlights students' performance in classroom teaching and their learning process is multimodalized, more modalities should be taken into evaluation system. Firstly, the means of evaluation should not be restricted to traditional written examination, and other imformantionized methods could be adopted, such as online examination, oral test and exercitation. Secondly, in oral test, especially in situational dialogue, modalities involved in students' performance including language, gesture, tone, and eye contact should be given adequate consideration when teachers are marking. Thirdly, students' records kept in the online learning database and on open sourse learning platforms should also be taken as an important component of evaluation system.

\section{b) Interactive assesment:}

As one of the fundamental theories that back up the proposed mode, CBI shows a significant departure from traditional College English teaching in that English proficiency is realized by shifting the focus of instruction form the teaching of language skills to the learning of subject matter in English. Therefore, in evaluation, linguistic proficiency should not be separated from conceptual understanding and these two capacities should be integrated into a whole. In this sense, an interactive assessment is needed. Firstly, students would be required to integrate information, to form and articulate their own points of view concerning given subject matter, rather than only analyze an English discourse linguistically. English culture, literature, geography, history and even knowledge related students' majors could be included in written examination. Secondly, students are not required to complete the primarily discrete, de-contextualized tasks but the tasks on the level of discourse. Thirdly, teachers are no longer the only one to evaluate but students, especially those who are in the same group could assess each other in terms of commitment, conscientiousness, team work, and leadership. Moreover, their self-assessment also counts.

\section{Conclusion}

Digitization, multimodality, individuation, and general education are symptomatic of today's higher education worldwide. With an unerring grasp of the need of social development and students' preference for learning in the information age, this study attempts to propose a flipped classroom in multimodal CBI College English teaching. Through discussion, it is proved that it is reasonable and feasible to integrate the theory of MDA, CBI and the idea of the flipped classroom into a College English teaching mode. In the matter of teaching facilities and media, the theory of MDA makes it possible to study how to select and coordinate multiple modalities involved in teaching for maximum benefit. With regard to teaching content, CBI formulates a practical plan of embedding English leaning in learning subject matter in English. Most importantly, the idea of the flipped classroom helps radicate a cardinal principle for the two aspects above by advocating student-centered teaching. The proposed mode would be dynamic and efficient by interesting students and encouraging them to do inquiry learning.

However, this study is merely a tentative step in the study of the flipped classroom in multimodal CBI College English teaching in that the discussion is just a theoretical study and limited to the rationality, necessity, feasibility, formation and potential problems of this mode. Further study can be done in the following aspects: Firstly, the findings should be crystallized into a concrete model which include specific proposals of each component of the curriculum and every stage of teaching; secondly, empirical study based on a quantitative statistical research is needed to prove the rationality and feasibility of the concrete model; thirdly, with the help of action research, the concrete model is supposed to be modified as it is put into practice; fourthly, in-depth study should be done to explore the possibility of the widespread use of the concrete model in English teaching in China.

\section{REFERENCES}

[1] Alexander A. Planning Your Flipped Classroom. http:moodle. Oakland.k12.us/os/mod/assign/view. Php?id=60659, 2103

[2] Baker JW. The Classroom Flip: Using Web Course Management Tools to Become the Guide by the Side[A]. In: Chambers JA(ed) Selected Papers From the $11^{\text {th }}$ International Conference on College Teaching and Learning[C]. Florida Cimmunty College, Jacksonville,2000. 9-17,

[3] Bates SP, Galloway RK The inverted classroom in a large enrolment introductory physics course: a case study[A]. Proc HEA STEM learn Teach Conf[C]. doi:10.11120/stem.hea.2012.071, 2012

[4] Bishop JL, Verleger MA. The Flipped Classroom: A Survey of the Research[A]. Proceedings of the $120^{\text {th }}$ American Society Of Engineering Education Annual Conference and Exposition[C], Atlanta, 2013

[5] Brinton D M, Snow M A \& Wesche M B. Content-Based Second Language Instruction [M]. New York: Newbury House, 1989. 
[6] Butt A. Students Views on the Use of a Flipped Classroom Approach: Evidence From Australia[J]. Bus Educ Accred6(1) , 2014.33-34

[7] Dawes K, Fox M, The Partially Flipped Classroom[J]. Indep Teach Mag11(1), 2013

[8] Ferreri SPP, O'Connor SKP. Redesign of a Large Lecture Course into a Small-group Learning Course[J]. Am J Pharm Educ 77(1), 2013

[9] Halliday, M. A. K. Language as social semiotic: The social interpretation of language and meaning [M]. London: Edward Arnold, 1978

[10] Hannafin M, Hill J, Land S. Student-centered Learning and Interactive Multimodia: Status, Issues, and Implication[J]. Contemp Educ 68(2), 1997.94-99

[11] Kim MK, Kim SM, Khera O, Getman J. The Exp;erence of Three Flipped Classrooms in an Urban Ubniverstity: An Exploration of Design Principle[J].Internet High Educ(22), 2014. 37-50

[12] Krahnke, K. , Approach to Syllabus Design for Foreign Language Teaching[M]. New York: Prentice Hall, 1987

[13] Kress, G. \& van Leeuwen, T. Reading images [M]. Geelong: Daekin UP, 1990.

[14] Kress, G. \& van Leeuwen, T. Multimodality Discourse: The modes and media of contemporary communication [M]. London: Arnold, 2001

[15] Lage MJ, Platt GJ, Treglia M. Inverting the Classroom: A Gateway to Creating an Inclusive Learning Environment[J]. $J$ Econ Educ 31(1), 2000

[16] Lim, V. F. Developing an integrative multi-semiotic model [A]. In O'Halloran, K.L. (ed.), MDA: Systemic-functional perspective [C]. New York: Continuum, 2004. 220- 245.

[17] Mazur E. Farewell, Lecture? [J]. Science 323(5910), 2009

[18] O'Toole, M. The language of displayed art [M]. London: Leicester UP, 1994

[19] Stoller, F. L. Project Work: A Means to Promote Language and Content. [J]. English Teaching Forum, 35(4), 1997

[20] Strayer JF. How Learning in an Inverted Classroom Influences Cooperation, Innovation and Task Orientation[J]. Learn Environ Res 15, 2012.171-193

[21] Stryker. S. B. \& B. L. Leaver, Content-based Instruction in Foreign Language Education [M]. Washington : Georgetown University Press, 1997.

[22] Van Leeuven, T. \& Jewitt, C. (eds.). Handbook of Visual Analysis [M]. London: Sage, 2000.

[23] Chen Yunru \& Gao Xiaofang. Interpretation of the Repesentational Meaning of Movie Posters from the Perspective of Multimodal discourse analysis[A], Proceedings of the International Conference on Education, Language, Art and Intercutural Communication[C], Zhengzhou, 2014

[24] $\mathrm{Hu}$ Zhuanglin..Multimodalityity in Social Semiotics[J]. Language Teaching and Linguistic Studies, 2007,(1) :1-10 (in Chinese)

[25] Huang Guowen. Theory and Practice of Discoures Analysis[M]. Shanghai: Shanghai Foreign Language Education Press, 2001

[26] Li Zhanzi. Social Semiotic Analysis of Multimodality Discourse [J]. Foreign Language Research, 2003, (5):1-4 (in Chinese)

[27] Sun Chunlei. On Content-Based Instruction Assessemnt[J]. Journal of Chongqing Institute of Technology, 2000, (4):91-94

[28] Wang Shixian.CBI- The Direction of Reading Instruction of English Major[J]. Forein Language Worl, 1994(2)

[29] Zhang Delu. On a Synthetic Theoritical Framework for MDA [J]. Foreign Language Research, 2009, (1):24-30 (in Chinese)

[30] Zhu Yongsheng. Theory and Methodology of MDA [J]. Foreign Language Research, 2007, (5):82-86 (in Chinese) 